\title{
NÍVEL DE DISCLOSURE SOCIOAMBIENTAL: UMA ANÁLISE COMPARATIVA ENTRE EMPRESAS BRASILEIRAS DE ACORDO COM O POTENCIAL DE AGRESSÃO AO MEIO AMBIENTE
}

\author{
DEGREE OF SOCIAL AND ENVIRONMENTAL DISCLOSURE: \\ A COMPARATIVE ANALYSIS OF BRAZILIAN COMPANIES \\ ACCORDING TO THE LEVEL OF SECTOR \\ IMPACT TO THE ENVIRONMENT
}

Data de submissão: $21 / 12 / 2016$ Aceite: $22 / 10 / 2017$

Dante Baiardo Cavalcante Viana Junior ${ }^{1}$ Vicente Lima Crisóstomo 2

\section{RESUMO}

O objetivo deste estudo é investigar o nível de disclosure socioambiental da empresa brasileira. Por meio de análise léxica, verifica-se a frequência de menção a 77 palavras e expressões-chaves relacionadas à divulgação ambiental e social nos relatórios obrigatórios da empresa. Calcula-se então seis índices de disclosure, sendo dois relativos à evidenciação de caráter ambiental, dois referentes à divulgação social, e dois associados à divulgação socioambiental como um todo. Foram consultadas as Demonstrações Financeiras Anuais Completas de 351 empresas brasileiras oriundas de 16 diferentes setores da economia, compreendendo setores explicitamente apontados como de impacto ambiental pela Política Nacional do Meio Ambiente (PNMA) e outros setores, no período 2010-2014. Os achados revelam que empresas classificadas como de mais alto impacto ambiental apresentam, em geral, índices mais elevados de disclosure social e ambiental. Os resultados são robustos para diferentes métricas do indicador de disclosure, como também para testes paramétricos e não paramétricos. A maior divulgação socioambiental em relatórios financeiros, por parte de empresas classificadas pela legislação brasileira como de alto impacto ambiental, está na direção da proposta de um possível efeito enforcement resultante da legislação ambiental, que parece ser capaz de pressionar as empresas mais ambientalmente impactantes a apresentarem um mais alto nível de divulgação de informação socioambiental.

Palavras-chave: Disclosure socioambiental. Política Nacional de Meio Ambiente. Impacto ambiental.

\footnotetext{
1 Possui graduação em Ciências Contábeis pela Universidade Federal do Ceará, UFC e mestrado em andamento em Administração e Controladoria pela Universidade Federal do Ceará, UFC. Fortaleza. Ceará. Brasil. E-mail: dantebcviana@gmail.com

2 Possui graduação em Ciências Contábeis pela Universidade Federal do Ceará, UFC, mestrado em Ciências da Computação pela Universidade Federal de Santa Catarina, UFSC e doutorado em Nuevas Tendencias En Dirección de Empresas pela Universidad de Valladolid, UVa, Espanha. Atualmente é professor do Departamento de Ciências Contábeis/Faculdade de Economia da Universidade Federal do Ceará. Fortaleza. Ceará. Brasil. E-mail: vicentelc@gmail.com
} 


\section{ABSTRACT}

The purpose of the study is evaluating the level of social and environmental disclosure of the Brazilian company. By means of lexical analysis, we count the frequency of appearance of 77 key terms related to environmental and social disclosure in firm financial reports. Six indices for disclosure are calculated, being two relative to environmental aspects, two related to social disclosure, and two associated with socio-environmental disclosure as a whole. We analyzed complete annual financial reports of 351 Brazilian companies from 16 different sectors, comprising sectors classified with relevant environmental impact, according to the National Environmental Policy (PNMA) and others, in the period 2010-2014. The findings signal that companies classified with greater environmental impact indeed present higher rates of social and environmental disclosure. Results are robust for different metrics of the disclosure indicator, as well as for parametric and non-parametric tests. The more pronounced socio-environmental disclosure by firms classified as with high environmental impact matches the proposal of the enforcement effect. The Brazilian environmental law could be an important trigger to foster social and environmental disclosure of firms with greater environmental impact.

Keywords: Socio-environmental disclosure. Environment Policy in Brazil. Environmental impact.

\section{INTRODUÇÃO}

Em função da crescente conscientização por parte da sociedade em geral acerca das questões ambientais, percebe-se que a Contabilidade, enquanto importante instrumento do processo de disclosure, parece exercer relevante papel nas organizações para o suprimento de demandas informacionais relacionadas à questão ambiental. Nesse sentido, é relevante a discussão sobre o disclosure voluntário de informações socioambientais realizado pelas firmas, uma vez que tal divulgação de informações gera custos às empresas. Para compreender os motivos que levam as organizações a adotarem o disclosure socioambiental, estudiosos ao longo das últimas décadas utilizaram diversas teorias, como, por exemplo, a teoria dos stakeholders (FREEMAN; PHILLIPS, 2002) e a teoria da legitimidade (SUCHMAN, 1995).

Diante dos múltiplos interesses presentes na sociedade moderna quanto à gestão e ao equilíbrio ambiental, é compreensível a expressiva atuação do Estado nas questões relativas à interferência das atividades empresariais no meio ambiente, principalmente definindo um arcabouço legal e regulatório com o objetivo de prover o desenvolvimento econômico preservando a qualidade de vida no ambiente (SILVA; QUELHAS, 2006). Nesse contexto, surgiu a Política Nacional do Meio Ambiente (PNMA), instaurada por meio da Lei n.o 6.938 de 1981, que apresenta como objetivo a preservação, melhoria e recuperação da qualidade ambiental propícia à vida, visando assegurar condições ao desenvolvimento socioeconômico, aos interesses da segurança nacional e à proteção da dignidade da vida humana.

Ao longo dos anos, desde a sua promulgação em 1981, diversas peças jurídicas alteraram a PNMA. Mais recentemente, a Lei n.o 10.165 de 2000 alterou a PNMA, incorporando ao normativo jurídico a Taxa de Controle e Fiscalização Ambiental (TCFA) - tributo cobrado das organizações cujas atividades são classificadas pela referida norma como de alto, médio e baixo impacto ambiental. Nesse sentido, Crisóstomo, Souza e Parente (2012) comentam que a classificação realizada pela Lei n. 10.165/2000 - ao categorizar os setores econômicos mediante seu potencial efeito danoso ao meio ambiente - parece gerar algumas implicações à forma como as empresas são vistas perante a sociedade, sinalizando ao mercado o potencial impacto de poluição das atividades empresariais e, consequentemente, os padrões de qualidade que lhes permitam minimizar os danos ao meio ambiente. 
É nessa conjectura que se observam, na literatura nacional, estudos que se dedicaram a investigar os reflexos da classificação das atividades empresariais como de baixo, médio e alto impacto ambiental, proposta pela Lei n. 10.165/2000, no nível de evidenciação de informações socioambientais das firmas (CRISÓSTOMO; SOUZA; PARENTE, 2012; FERNANDES, 2013; MACHADO; MACHADO; MURCIA, 2011; MURCIA et al., 2008; ROVER; BORBA; MURCIA, 2009; SILVA et al., 2015; VIEIRA; ARRUDA; LIMA, 2014).

Motivada pela ampla discussão, no meio tanto científico quanto social, acerca do disclosure socioambiental praticado pelas empresas, a presente pesquisa parte da seguinte questão-problema: qual é o nível de disclosure socioambiental praticado pelas empresas brasileiras pertencentes aos setores de alto, médio, baixo e sem impacto ambiental, conforme Lei n. 10.165/2000? Assim, objetiva-se investigar o nível de evidenciação socioambiental das empresas listadas na BM\&FBovespa classificadas como potencialmente poluidoras, conforme delineamento proposto pela PNMA.

Tendo em vista a ampla discussão científica já existente acerca dos níveis de evidenciação de empresas brasileiras pertencentes a setores tidos como potencialmente poluidores, conforme a Lei $n .0$ 10.165/2000, o presente estudo contribui para a literatura em torno da temática em pelos menos dois aspectos: (i) pelo número consistente de observações anuais de empresas utilizadas, abrangendo 1.671 observações; e (ii) pela técnica de mensuração da divulgação socioambiental, realizada por meio de uma análise léxica de contagem de palavras e expressões, ainda pouco explorada em estudos nacionais sobre a temática.

\section{REFERENCIAL TEÓRICO E HIPÓTESES}

\subsection{Disclosure socioambiental}

A Contabilidade, enquanto ferramenta de gestão, tem a função de prestar informações úteis aos mais diversos tipos de stakeholders. Dessa forma, o disclosure socioambiental torna-se parte desse domínio profissional. De um modo geral, ele pode ser entendido como processo de comunicação das ações de efeitos sociais e ambientais das organizações tanto para determinados grupos de interesse quanto para a sociedade em geral. Como tal, o disclosure socioambiental destina-se a estender a prestação de contas das empresas, indo além do papel tradicional da prestação de contas financeiras aos acionistas. Essa extensão se baseia no pressuposto de que as empresas têm amplas responsabilidades sobre o ambiente em que operam, que ultrapassam a simples responsabilidade financeira (CARDOSO; DE LUCA; ALMEIDA, 2016; RIZK; DIXON; WOODHEAD, 2008).

As recentes tragédias climáticas propagadas nos mais diversos canais de mídia, muitas delas advindas do uso desenfreado e sem comedimento dos recursos naturais por parte das empresas, reiteram na sociedade necessidades mais urgentes da divulgação de informações sobre ações de cunho social e ambiental por parte das organizações. Observa-se, na literatura acerca da temática, que as primeiras discussões sobre o assunto datam das décadas de 1970 e, mais fortemente, de 1980 (BURCHELL et al., 1980; PRESTON, 1981; PRESTON, 1978).

Nesse sentido, torna-se pertinente compreender as motivações da evidenciação socioambiental. De um modo amplo, o disclosure socioambiental ocorre mais frequentemente de forma voluntária (MAPURUNGA; LIMA; HOLANDA, 2015), sendo obrigatório quando exigido por lei, como é o caso em poucos países, a exemplo da China, Dinamarca, Malásia e África do Sul (IOANNOU; SERAFEIM, 2014). No Brasil, de forma geral, o disclosure socioambiental é voluntário. Entretanto, ressalta-se que em alguns setores, em função principalmente de seu vínculo com o Estado e, como consequência, de terem uma interação maior com a sociedade no que diz respeito à prestação de contas, a divulgação socioambiental ocorre de forma compulsória, como é 
o caso do Setor Elétrico, que, por meio do diploma legal Despacho n. 3034/2006, da Agência Nacional de Energia Elétrica (ANEEL), é obrigado a divulgar relatórios anuais discorrendo sobre suas principais atividades e políticas ambientais (BRAGA; SILVA; SANTOS, 2014).

Diante dos gastos de preparação e divulgação com os quais as empresas necessitam arcar quando adotam o disclosure socioambiental, questionam-se os motivos que as levam a divulgarem informações ambientais e sociais em seus relatórios de sustentabilidade ou mesmo em relatórios financeiros. Algumas teorias têm sido propostas para explicar essa motivação, como a teoria da legitimidade e a teoria dos stakeholders - as mais frequentemente mencionadas na literatura (TEIXEIRA; RIBEIRO, 2014).

Dos pressupostos da teoria da legitimidade - intrinsicamente ligada à teoria dos contratos -, emana a concepção de que todas as organizações atuantes no mercado, sejam elas com ou sem fins lucrativos, operam na sociedade por meio de contratos sociais - implícitos ou explícitos. Sob essa conjectura, a sobrevivência e o crescimento das organizações estariam baseados (i) na entrega de alguns dos produtos e serviços desejados pela sociedade em geral e (ii) na distribuição dos direitos econômicos e sociais ou de benefícios políticos para a coletividade a partir da qual deriva o poder das organizações. Dessa maneira, as empresas devem de forma constante satisfazer os testes individuais de legitimidade advindos da sociedade, de modo que obtenham aprovação dos indivíduos presentes no meio em que operam (SHOCKER; SETHI, 1973).

Suchman (1995) argumenta ser a legitimidade uma percepção ou mesmo suposição generalizada, por parte da coletividade, de que as ações de uma entidade são desejáveis, adequadas ou se enquadram dentro de algum sistema de construção social de normas, valores, crenças e definições. Em outras palavras, o status de legítima é conquistado pela organização quando esta se alinha ao sistema de valores previamente estabelecido pelo meio no qual opera. Também utilizada para explicar fenômenos em ciências do comportamento, a teoria da legitimidade começa a ser empregada na área contábil, particularmente em pesquisas que buscam explicações para a adoção de certos mecanismos de evidenciação. Dessa forma, é de esperar-se que as organizações façam uso de suas políticas de divulgação de ações socioambientais como meio de alcançar, manter ou recuperar sua legitimidade (DIAS FILHO, 2012).

Sob um diferente enfoque, inserida dentro dos conceitos de gestão organizacional estratégica e ética, a teoria dos stakeholders tem como ideia central a concepção de que o sucesso de uma organização depende de quão bem ela consegue relacionar-se com seus grupos de interesse, tais como clientes, funcionários, fornecedores, comunidades, financiadores e outros atores que podem afetar a realização de sua finalidade. Nessa perspectiva, o principal trabalho da gestão seria manter o apoio de todos esses grupos, equilibrando e maximizando seus interesses ao longo do tempo (FREEMAN; PHILLIPS, 2002).

Também discutida em outras disciplinas, como no Direito (LAMPE, 2001) e na Economia (BARTON; HILL; SUNDARAM, 1989), a teoria dos stakeholders é utilizada como arcabouço teórico para explicar as práticas de Responsabilidade Social Corporativa em diversos países, como, por exemplo, em Taiwan (HUANG; KUNG, 2010), no Reino Unido (HARTE; OWEN, 1991), na Itália (BOESSO; KUMAR, 2007), na China (LIU; ANBUMOZHI, 2009), na Espanha (REVERTE, 2009), na Austrália (TEN, 2007) e na Malásia (TEN, 2004). Sob essa perspectiva, a ideia é que os avanços dos níveis de conscientização ambiental por parte dos stakeholders criam nas empresas a necessidade de aumentar seu planejamento social corporativo para atender aos interesses de grupos da sociedade que até pouco tempo poderiam ser considerados como de pouca relevância, adaptando-se, portanto, às novas demandas sociais (TEN, 2007).

Dessa forma, ante as pressões advindas de stakeholders externos, acredita-se que o disclosure socioambiental poderia não somente atender aos interesses destes - diminuindo a assi- 
metria de informação empresa-mercado -, mas também influenciar percepções financeiras por parte dos investidores (BRAMMER; PAVELIN, 2008). Assim, também se destacam diversos estudos recentes no Brasil que buscaram justificativas para o disclosure socioambiental com base na teoria dos stakeholders (BOMFIM; TEIXEIRA; MONTE, 2015; CORREA; GONÇALVES; MORAES, 2015; FERNANDES, 2013; SANTANA et al., 2015; SOUSA et al., 2014; TANNURIL; VAN BELLEN, 2014).

Diante das discussões sobre as possíveis causas para a divulgação socioambiental por parte das organizações, comente-se ainda o papel do Estado e sua atuação na promoção do bem comum, considerando o meio ambiente como um recurso de uso comum das pessoas, além de atuar na gestão e defesa dos recursos ambientais por intermédio de diversos atos normativos legais (CRUZ; MARQUES; FERREIRA, 2009), o que poderia, direta ou indiretamente, repercutir na motivação, ou não, das práticas de divulgação corporativa.

\subsection{A Política Nacional de Meio Ambiente e suas implicações sobre o disclosure}

Para a satisfação das necessidades e das aspirações da coletividade, a sociedade interfere no ambiente, ocasionando alterações nas suas condições e na sua qualidade. Dessa forma, mediante a complexidade e heterogeneidade dos interesses envolvidos entre todos os agentes que acabam por impactar o meio ambiente, a resolução dos conflitos ambientais requer uma condução compartida no processo de gestão ambiental (AGRA FILHO, 2008).

Nessa discussão, Silva e Quelhas (2006) ensinam que o Estado exerce um papel relevante nas questões relativas à interferência das atividades empresariais no meio ambiente, principalmente definindo um arcabouço legal e regulatório com o objetivo de prover o desenvolvimento econômico preservando a qualidade de vida no ambiente. Surge, nesse contexto, a Lei n.․․ 6.938 de 1981 - que dispõe sobre a PNMA, trazendo como um de seus objetivos a compatibilização do desenvolvimento econômico-social mediante a preservação dos recursos ambientais -, bem como a Constituição de 1988, a primeira constituição brasileira a dedicar um capítulo ao meio ambiente e à sua proteção, reconhecida como uma das mais avançadas, segundo alguns estudiosos, em comparação com os textos de outros países, ao trazer uma visão holística da proteção ao meio ambiente como sistema ecológico integrado e autônomo (FONTENELLE, 2004).

A partir da Lei n.o 6.938/81 e da promulgação da Constituição Federal de 1988, surgiram leis, decretos e resoluções que objetivaram a utilização racional, a conservação e a proteção efetiva dos recursos naturais, podendo-se destacar, conforme sugerem Borges, Rezende e Pereira (2009): (i) a criação do Programa Nossa Natureza, por meio do Decreto n.o 96.944 de 1988, visando desenvolver a educação ambiental e a conscientização pública para a conservação da natureza; (ii) a promulgação da Lei n.o 7.735 de 1989, constituindo o Instituto Brasileiro do Meio Ambiente e dos Recursos Naturais Renováveis (Ibama); (iii) a criação do Ministério do Meio Ambiente, dos Recursos Hídricos e da Amazônia Legal, por meio da Lei n. 8.490 de 1992, que, em 1999, via reestruturação ministerial do Decreto n. 2.972, passaria denominar-se Ministério do Meio Ambiente, constituído até os dias atuais; (iv) e a promulgação de importantes leis como, por exemplo, a Lei de Crimes Ambientais (Lei n. 9.605/1998) e a Lei n. 9.984/2000, que cria a Agência Nacional das Águas (ANA).

Ainda no que diz respeito aos avanços no ordenamento jurídico brasileiro quanto à temática ambiental, ressalta-se a Lei n.o 10.165 de 2000, que altera a Lei n. 0 6.938/1981, instituindo a Taxa de Controle e Fiscalização Ambiental (TCFA), tributo cujo fato gerador é o exercício regular do poder de polícia para controle e fiscalização das atividades potencialmente poluidoras e utilizadoras de recursos naturais. Nessa discussão, ressalta-se que o pagamento da TCFA é ba- 
seado em dois critérios: no grau de poluição da atividade e no porte da empresa. No que tange ao grau de poluição, as atividades desenvolvidas pelas empresas são classificadas como sendo de baixo, médio e alto impacto ambiental. Dessa forma, empresas de maior porte e que exerçam atividades de alto impacto terão mais elevadas TCFA.

A literatura já tem dedicado atenção à Lei n.o 10.165/2000, especificamente no que se concerne à classificação das atividades das empresas como sendo de alto, médio e baixo impacto ambiental (CRISÓSTOMO; SOUZA; PARENTE, 2012; FERNANDES, 2013; MACHADO; MACHADO; MURCIA, 2011; MURCIA et al., 2008; ROVER; BORBA; MURCIA, 2009; SILVA et al., 2015; VIEIRA; ARRUDA; LIMA, 2014). Crisóstomo, Souza e Parente (2012), por exemplo, analisaram as práticas de responsabilidade socioambiental divulgadas no Balanço Social de empresas brasileiras no período de 1996 a 2008. Os autores avaliaram de forma comparativa a responsabilidade ambiental entre os setores considerados como de maior potencial de impacto ambiental, utilizando como parâmetro a classificação da Lei n.o 10.165/2000, a fim de averiguar se a promulgação desse instrumento legal contribuiu para um nível mais elevado de responsabilidade ambiental das empresas brasileiras. Os resultados obtidos sugerem que as empresas brasileiras apresentaram indicadores de responsabilidade ambiental mais elevados após o advento da Lei n.․⒑165/2000 e que as empresas de setores classificados pelo referido instrumento legal como ambientalmente mais impactantes têm indicadores de responsabilidade ambiental superior às demais.

Na discussão sobre o mesmo tema, Rover, Borba e Murcia (2009) investigaram as características do disclosure voluntário ambiental de empresas brasileiras classificadas como de alto impacto, segundo a Lei n.o 10.165/2000, tanto nas Demonstrações Financeiras Padronizadas (DFPs) quanto nos Relatórios de Sustentabilidade (RS). Utilizando-se de análise de conteúdo para uma amostra de 57 empresas no período de 2005 a 2007, os resultados mostraram que as empresas usaram 6.182 sentenças ambientais, sendo $73 \%$ divulgadas nos RS, e $27 \%$, nas DFPs, e que a maior parte da evidenciação foi declarativa, do tipo positiva e com referência temporal não especificada. Dessa forma, os autores concluem que a pesquisa corrobora a teoria da divulgação voluntária, uma vez que as empresas divulgaram voluntariamente poucas informações negativas a respeito de suas práticas ambientais.

Diante do exposto em relação à PNMA, parece relevante a classificação de setores da economia promovida pela Lei $n$. o 10.165/2000, ao deixar claro à sociedade e ao mercado como cada atividade econômica está sendo considerada em relação ao meio ambiente e quais obrigações as empresas classificadas como potencialmente poluidoras, sejam de baixo, médio ou alto impacto ambiental, têm para manterem padrões de qualidade que thes permitam minimizar os danos ao meio ambiente (CRISÓSTOMO; SOUZA; PARENTE, 2012).

Nesse sentido, a teoria dos stakeholders vai ao encontro do exposto no sentido de que se poderia esperar níveis maiores de disclosure socioambiental por parte de empresas classificadas pela Lei n.o 10.165/2000 como de maior impacto ambiental em função das pressões exercidas pelo mercado sobre essas empresas, o que culminaria em uma maior preocupação de sua gestão a fim de atender a tais exigências. Sob o enfoque da teoria dos stakeholders, empresas com impacto ambiental mais elevado divulgariam mais com o intuito de atender às demandas de informações por parte dos vários stakeholders, os quais estão cada dia mais conscientes e ativos no que se refere às questões ambientais.

Nessa perspectiva, destaca-se, ainda, o artigo 17-C da Lei n. 10.165/2000, ao postular por meio do $\S 1$ ㅇque as empresas classificadas pela lei como de alto, médio e baixo impacto ambiental devem "entregar até o dia 31 de março de cada ano o relatório das atividades exercidas no ano anterior, cujo modelo será definido pelo lbama, para o fim de colaborar com os procedi- 
mentos de controle e fiscalização". Essa previsão legal está em sintonia com as proposições da teoria dos stakeholders, uma vez que o stakeholder Governo, representante de toda a sociedade, tem um papel ativo no sentido do obrigar a divulgação de informações sobre ações da empresa como forma de dar mais transparência a suas ações. Apesar de tal obrigação ser específica para um relatório enviado ao agente governamental, é provável que haja um reflexo positivo na divulgação para os demais stakeholders por parte das empresas classificadas como mais impactantes no meio ambiente. Portanto, seria plausível considerar que o volume de informações de cunho ambiental já divulgado em função deste normativo legal facilitaria a elaboração de relatórios de sustentabilidade ou a inserção dessas informações em demonstrações financeiras.

Nesse contexto, há uma linha de pesquisa que tem defendido a relação positiva entre a sensibilidade ambiental das atividades da empresa e o nível de disclosure de caráter ambiental, ou seja, a ideia de que, quanto maior for o potencial de impacto ambiental da empresa, mais alto tende a ser o nível de divulgação socioambiental (AHMAD SALLET; MOHAMMAD, 2003; CORMIER; GORDON, 2001; DEEGAN; GORDON, 1996; FROST; WILMSHURST, 2000; LIU; ANBUMOZHI, 2009; SMITH; YAHYA; AMIRUDDIN, 2007). Frost e Wilmshurst (2000), por exemplo, comentam que níveis mais elevados de evidenciação por parte de setores ambientalmente mais sensíveis poderiam ser justificados, dentre outros fatores, pelas diferentes percepções e expectativas dos stakeholders sobre esses setores. Os autores exemplificam que empresas de varejo adotarão procedimentos de política e gestão ambiental diferentes dos adotados por empresas de dimensões semelhantes na indústria química. Em outras palavras, o aumento do nível de danos socioambientais das atividades corporativas eleva, de forma consequente, a minuciosidade das análises dos stakeholders. Dessa forma, por estarem visivelmente mais expostas e passíveis de críticas, julgamentos e até penalidades pecuniárias, a gestão das empresas desses setores estaria mais sensível às pressões por mais ação socioambiental e respectiva divulgação, até mesmo como estratégia de legitimação de suas ações, como proposto na hipótese a seguir.

Hipótese: o nível de disclosure socioambiental de setores cujas atividades são consideradas como de alto impacto ambiental é superior àquele de outros setores.

\section{METODOLOGIA}

\subsection{Amostra}

Utilizou-se uma amostra de 351 companhias listadas na BM\&FBovespa pertencentes a 16 diferentes segmentos econômicos, conforme classificação proposta pelo North American Industry Classification System (NAICS) e pela Economática. O período de análise foi 2010 a 2014, compreendendo um total de 1.755 observações anuais de 351 empresas. No entanto, devido à metodologia proposta para quantificação do disclosure, conforme sessão 4.2, algumas observações foram descartadas pelo fato de as demonstrações financeiras utilizadas para o cálculo dos índices apresentarem-se no formato de imagem, inviabilizando a análise léxica pela busca de palavras e expressõeschaves. Além disso, outras observações foram expurgadas da análise pelo fato de os documentos disponibilizados pelas companhias estarem corrompidos ou por simplesmente a empresa não ter realizado a divulgação. Dessa forma, a amostra final é composta por 1.671 observações.

A Tabela 1, a seguir, apresenta a distribuição das observações deste estudo distribuídas ao longo do período de análise (2010-2014) por segmento econômico, conforme classificação do NAICS (2017) e da Economática (2017). 
Tabela 1 - Divisão da amostra por setor econômico (2010-2014)

\begin{tabular}{cccccccc}
\hline SETOR DE ATUAÇÃo & $\mathbf{2 0 1 0}$ & $\mathbf{2 0 1 1}$ & $\mathbf{2 0 1 2}$ & $\mathbf{2 0 1 3}$ & $\mathbf{2 0 1 4}$ & TOTAL & \% \\
\hline Construção & 18 & 17 & 18 & 18 & 20 & 91 & 5,4 \\
Transporte & 18 & 17 & 18 & 18 & 21 & 92 & 5,5 \\
Negócios & 29 & 29 & 32 & 32 & 33 & 155 & 9,3 \\
Comunicação e Mídia & 13 & 13 & 12 & 11 & 12 & 61 & 3,7 \\
Energia Elétrica, Água e Gás & 51 & 52 & 53 & 53 & 52 & 261 & 15,6 \\
Eletrônicos & 8 & 9 & 8 & 10 & 10 & 45 & 2,7 \\
Serviços de Finanças & 31 & 34 & 33 & 35 & 35 & 168 & 10,1 \\
Alimentos & 16 & 17 & 16 & 14 & 15 & 78 & 4,7 \\
Mineração e Metais & 7 & 6 & 7 & 8 & 8 & 36 & 2,2 \\
Mineração e Siderurgia & 25 & 27 & 27 & 28 & 29 & 136 & 8,1 \\
Industria de Veículos & 11 & 11 & 12 & 12 & 12 & 58 & 3,5 \\
Petróleo e Gás & 5 & 4 & 4 & 4 & 6 & 23 & 1,4 \\
Têxtil & 23 & 23 & 22 & 23 & 24 & 115 & 6,9 \\
Comércio e Varejo & 15 & 16 & 15 & 17 & 17 & 80 & 4,8 \\
Madeira e Papel & 7 & 8 & 8 & 8 & 8 & 39 & 2,3 \\
Outros & 42 & 46 & 49 & 47 & 49 & 233 & 13,9 \\
\hline TOTAL & $\mathbf{3 1 9}$ & $\mathbf{3 2 9}$ & $\mathbf{3 3 4}$ & $\mathbf{3 3 8}$ & $\mathbf{3 5 1}$ & $\mathbf{1 . 6 7 1}$ & $\mathbf{1 0 0}$ \\
\hline
\end{tabular}

Fonte: elaborada pelos autores.

A Tabela 2 retrata a amostra segregando as empresas pelo nível de impacto ambiental de suas atividades, conforme a Lei n.o 10.165/2000, e aglutinando as observações como sendo de baixo impacto, médio impacto, alto impacto e sem impacto, sendo este último grupo constituído de empresas pertencentes a segmentos não contemplados pela lei em questão.

Tabela 2 - Divisão da amostra por setor de impacto (2010-2014)

\begin{tabular}{ccccccc}
\hline NÍVEL DE IMPACTO AMBIENTAL DO & $\mathbf{2 0 1 0}$ & $\mathbf{2 0 1 1}$ & $\mathbf{2 0 1 2}$ & $\mathbf{2 0 1 3}$ & $\mathbf{2 0 1 4}$ & TOTAL \\
SETOR & 146 & 153 & 156 & 160 & 167 & 782 \\
Sem Impacto & 4 & 4 & 4 & 4 & 4 & 20 \\
Baixo Impacto & 123 & 127 & 128 & 126 & 128 & 632 \\
Médio Impacto & 46 & 45 & 46 & 48 & 52 & 237 \\
Alto Impacto & $\mathbf{3 1 9}$ & $\mathbf{3 2 9}$ & $\mathbf{3 3 4}$ & $\mathbf{3 3 8}$ & $\mathbf{3 5 1}$ & $\mathbf{1 . 6 7 1}$ \\
\hline TOTAL & & &
\end{tabular}

Fonte: elaborada pelos autores.

\section{2. Índices de disclosure socioambiental}

Para a quantificação da evidenciação social e ambiental, fez-se a análise léxica das Demonstrações Financeiras Anuais Completas (DFAC) - relatório contábil de divulgação obrigatória pelas companhias listadas na BM\&FBovespa, conforme Instruções n.ㅇ 358/02, 480/09 e 481/09 da Comissão de Valores Mobiliários (CVM), como já realizado em trabalhos anteriores desenvolvidos no Brasil (OLIVEIRA; COELHO, 2014; PINHEIRO, 2015; ROVER; BORBA; MURCIA, 2009; SOUZA; SARLO NETO, 2014; TELLES; SALOTE, 2015). Este demonstrativo abrange, entre outros elementos, o relatório da administração, as demonstrações financeiras, o parecer da auditoria e a declaração da diretoria. A escolha das DFAC também se justifica pela padronização quanto à sua divulgação, sendo enviados à CVM obrigatoriamente. Por outro lado, os relatórios de sustentabilidade, por serem de caráter voluntário no Brasil, não apresentam uma nomenclatura padronizada. 
Realizou-se, assim, uma análise léxica dos relatórios de DFAC por meio da busca de palavras e expressões-chaves relacionadas com a divulgação ambiental e social seguindo metodologia amplamente adotada na literatura (GAMERSCHLAG; MÖLLER; VERBEETEN, 2011; MARQUEZAN et al., 2015; Muslu et al., 2015; SUTTIPUN; STANTON, 2012; VILLIERS; ALEXANDER, 2014). Com fundamentação matemática e estatística, a análise léxica consiste em um processo automatizado de busca de caracteres, palavras ou expressões que permite interpretar e fazer uma leitura adequada e dinâmica do objeto de investigação linguística (FREITAS; JANISSEK, 2000; FREITAS; MOSCAROLA, 2002). Esse tipo de procedimento não é mais rigoroso do que a análise de conteúdo clássica (BARDIN, 1977), permitindo, no entanto, um tratamento mais objetivo do texto analisado (FREITAS; MOSCAROLA, 2002).

Nesse sentido, a quantificação do disclosure por meio da busca de termos específicos reduz a subjetividade presente em diversos estudos que se utilizam da análise de conteúdo (GAMERSCHLAG; MÖLLER; VERBEETEN, 2011), uma vez que, nestes estudos, cabe ao pesquisador o julgamento sobre determinados aspectos do que se busca quantificar, como, por exemplo, decidir se determinada expressão relativa ao disclosure ambiental deveria ser classificada como positiva ou negativa. Outro fator considerado é a abrangência de maior contingente de relatórios que se pretende para um trabalho quantitativo.

A seleção das palavras referentes à divulgação ambiental e social foi baseada nas diretrizes de divulgação do Global Reporting Initiative (GRI) - referentes ao Modelo G4 (2016), especificamente com relação às categorias Ambiental e Social e seus respectivos indicadores - $\mathrm{e}$ em estudos anteriores que utilizaram metodologia semelhante para quantificação do disclosure socioambiental (GAMERSCHLAG; MÖLLER; VERBEETEN, 2011; MARQUEZAN et al., 2015; MUSLU et al., 2015; SUTTIPUN; STANTON, 2012; VILLIERS; ALEXANDER, 2014).

A Tabela 3, a seguir, sumariza as palavras e expressões pesquisadas nas DFAC das firmas relativas à divulgação de cunho ambiental e social, exibindo a frequência absoluta e relativa de cada uma e segregando-as entre empresas de setores potencialmente poluentes (contemplados pela PNMA - Lei n.o 10.165/2000) e não potencialmente poluentes. Observa-se que há expressões relativas ao aspecto ambiental com frequência mais elevada, como é o caso de: "Floresta", "Meio Ambiente" e "Sustentabilidade". Essas expressões mais frequentes parecem ser muito genéricas em contraste com aspectos importantes que são muito pouco mencionados, como é o caso de "Auditoria Ambiental" ou "Derramamento". Em relação às expressões de cunho social, também há certa predominância de palavras com significado mais amplo, como "Cultura", "Educação", "Emprego" e "Treinamento", o que parece denotar uma relevância concedida à relação com empregados, fato que não se confirma devido à baixíssima, ou nenhuma referência a elementos importantes como "Incentivo salarial", "Plano de Cargos e Salários" ou "Satisfação no trabalho".

Tabela 3 - Número de palavras ou expressões-chaves encontradas ao longo do período (2010-2014)

\begin{tabular}{|c|c|c|c|c|c|c|c|c|c|}
\hline \multirow[t]{2}{*}{$\begin{array}{l}\text { Palavras e Expres- } \\
\text { sões de Cunho } \\
\text { Ambiental }\end{array}$} & \multicolumn{2}{|c|}{$\begin{array}{l}\text { Empresas de } \\
\text { Setores não Po- } \\
\text { luentes }\end{array}$} & \multicolumn{2}{|c|}{$\begin{array}{l}\text { Empresas de } \\
\text { Setores Po- } \\
\text { tencialmente } \\
\text { Poluentes }\end{array}$} & \multirow[t]{2}{*}{$\begin{array}{c}\text { Palavras e Expres- } \\
\text { sões de } \\
\text { Cunho Social }\end{array}$} & \multicolumn{2}{|c|}{$\begin{array}{l}\text { Empresas de } \\
\text { Setores não } \\
\text { Poluentes }\end{array}$} & \multicolumn{2}{|c|}{$\begin{array}{l}\text { Empresas de Se- } \\
\text { tores Potencial- } \\
\text { mente Poluentes }\end{array}$} \\
\hline & $\mathrm{N}$ & $\%$ & $\mathrm{~N}$ & $\%$ & & $\mathrm{~N}$ & $\%$ & $\mathrm{~N}$ & $\%$ \\
\hline $\begin{array}{l}\text { Auditoria Ambien- } \\
\text { tal }\end{array}$ & 0 & 0,0 & 7 & 0,1 & Absenteísmo & 14 & 0,2 & 24 & 0,2 \\
\hline Biodiversidade & 70 & 1,5 & 139 & 1,2 & $\begin{array}{c}\text { Campanha(s) de } \\
\text { saúde }\end{array}$ & 1 & 0,0 & 7 & 0,0 \\
\hline $\begin{array}{c}\text { Conservação Am- } \\
\text { biental }\end{array}$ & 3 & 0,1 & 21 & 0,2 & Comunicação Interna & 39 & 0,5 & 44 & 0,3 \\
\hline Crédito de Carbono & 8 & 0,2 & 10 & 0,1 & Comunidade(s) & 554 & 7,5 & 1.822 & 13,0 \\
\hline
\end{tabular}


NÍVEL DE DISCLOSURE SOCIOAMBIENTAL:

UMA ANÁLISE COMPARATIVA ENTRE EMPRESAS BRASILEIRAS

DE ACORDO COM O POTENCIAL DE AGRESSÃO AO MEIO AMBIENTE

\begin{tabular}{|c|c|c|c|c|c|c|c|c|c|}
\hline $\mathrm{CO} 2$ & 137 & 2,9 & 156 & 1,3 & $\begin{array}{c}\text { Convenção(es) cole- } \\
\text { tiva(s) }\end{array}$ & 26 & 0,4 & 38 & 0,3 \\
\hline Custo Ambiental & 0 & 0,0 & 0 & 0,0 & Corrupção & 67 & 0,9 & 164 & 1,2 \\
\hline Dano Ambiental & 3 & 0,1 & 8 & 0,1 & Creche(s) & 67 & 0,9 & 344 & 2,5 \\
\hline Derramamento(s) & 0 & 0,0 & 21 & 0,2 & Cultura & 1.465 & 19,7 & 2.879 & 20,5 \\
\hline $\begin{array}{l}\text { Desenvolvimento } \\
\text { Sustentável }\end{array}$ & 217 & 4,5 & 472 & 3,9 & $\begin{array}{c}\text { Desenvolvimento } \\
\text { profissional }\end{array}$ & 88 & 1,2 & 222 & 1,6 \\
\hline Ecologia & 11 & 0,2 & 31 & 0,3 & Direitos humanos & 34 & 0,5 & 83 & 0,6 \\
\hline Ecológico & 16 & 0,3 & 60 & 0,5 & Educação & 1.350 & 18,2 & 1.649 & 11,7 \\
\hline $\begin{array}{l}\text { Educação Ambien- } \\
\text { tal }\end{array}$ & 43 & 0,9 & 365 & 3,0 & Emprego(s) & 1.405 & 18,9 & 3.124 & 22,3 \\
\hline Efeito Estufa & 142 & 3,0 & 266 & 2,2 & Fome & 370 & 5,0 & 672 & 4,8 \\
\hline Efluente(s) & 38 & 0,8 & 169 & 1,4 & $\begin{array}{l}\text { Incentivo(s) sala- } \\
\text { rial(is) }\end{array}$ & 0 & 0,0 & 0 & 0,0 \\
\hline Emissão de Gás & 22 & 0,5 & 54 & 0,4 & ISO 26000 & 0 & 0,0 & 10 & 0,1 \\
\hline Emissão Tóxica & 0 & 0,0 & 0 & 0,0 & Know-how & 25 & 0,3 & 19 & 0,1 \\
\hline Energia Eficiente & 2 & 0,0 & 8 & 0,1 & Lazer & 133 & 1,8 & 160 & 1,1 \\
\hline Energia Renovável & 20 & 0,4 & 261 & 2,2 & $\begin{array}{l}\text { Liberdade de asso- } \\
\text { ciação }\end{array}$ & 0 & 0,0 & 11 & 0,1 \\
\hline Energia Alternativa & 0 & 0,0 & 22 & 0,2 & Oportunidades Iguais & 1 & 0,0 & 2 & 0,0 \\
\hline Energia Sustentável & 2 & 0,0 & 70 & 0,6 & $\begin{array}{c}\text { Plano de Cargos e } \\
\text { Salários }\end{array}$ & 11 & 0,1 & 19 & 0,1 \\
\hline Fauna & 37 & 0,8 & 156 & 1,3 & Política(s) pública(s) & 19 & 0,3 & 5 & 0,0 \\
\hline Flora & 103 & 2,1 & 187 & 1,5 & Projeto(s) Social(is) & 122 & 1,6 & 264 & 1,9 \\
\hline Floresta & 1.125 & 23,4 & 2.177 & 18,0 & Recrutamento(s) & 101 & 1,4 & 209 & 1,5 \\
\hline Gestão Ambiental & 70 & 1,5 & 413 & 3,4 & Recursos humanos & 571 & 7,7 & 686 & 4,9 \\
\hline Impacto Ambiental & 68 & 1,4 & 133 & 1,1 & $\begin{array}{c}\text { Responsabilidade do } \\
\text { produto }\end{array}$ & 0 & 0,0 & 0 & 0,0 \\
\hline ISO 14001 & 38 & 0,8 & 239 & 2,0 & $\begin{array}{c}\text { Satisfação no tra- } \\
\text { balho }\end{array}$ & 0 & 0,0 & 0 & 0,0 \\
\hline Limpo & 73 & 1,5 & 108 & 0,9 & Saúde do cliente & 0 & 0,0 & 0 & 0,0 \\
\hline Lixo tóxico & 0 & 0,0 & 0 & 0,0 & Saúde ocupacional & 54 & 0,7 & 130 & 0,9 \\
\hline Meio Ambiental & 0 & 0,0 & 4 & 0,0 & Segurança do cliente & 1 & 0,0 & 0 & 0,0 \\
\hline Meio Ambiente & 543 & 11,3 & 2.248 & 18,6 & Trabalho forçado & 3 & 0,0 & 7 & 0,0 \\
\hline Ozônio & 0 & 0,0 & 15 & 0,1 & Trabalho infantil & 0 & 0,0 & 37 & 0,3 \\
\hline Passivo Ambiental & 41 & 0,9 & 44 & 0,4 & Treinamento(s) & 898 & 12,1 & 1.409 & 10,0 \\
\hline Poluição & 5 & 0,1 & 101 & 0,8 & & & & & \\
\hline Reciclagem & 126 & 2,6 & 261 & 2,2 & & & & & \\
\hline Recursos Naturais & 122 & 2,5 & 377 & 3,1 & & & & & \\
\hline Reflorestamento(s) & 176 & 3,7 & 369 & 3,1 & & & & & \\
\hline Resíduo(s) & 86 & 1,8 & 309 & 2,6 & & & & & \\
\hline Reutilização & 6 & 0,1 & 23 & 0,2 & & & & & \\
\hline Reutilizar & 4 & 0,1 & 27 & 0,2 & & & & & \\
\hline Risco Ambiental & 8 & 0,2 & 10 & 0,1 & & & & & \\
\hline Socioambiental & 292 & 6,1 & 458 & 3,8 & & & & & \\
\hline Sustentabilidade & 1.134 & 23,6 & 2.206 & 18,3 & & & & & \\
\hline Vazamento & 13 & 0,3 & 74 & 0,6 & & & & & \\
\hline TOTAL & 4.804 & 100,0 & 12.079 & 100,0 & TOTAL & 7.419 & 100,0 & 14.040 & 100,0 \\
\hline
\end{tabular}

Fonte: elaborada pelos autores.

A busca e quantificação das palavras e expressões foi realizada com o auxílio do software FineCount (Tilti Systems - FineCount: http://www.tilti.com/software-for-translators/finecount/), de uso profissional para tabulação e estratificação de diversos fatores em análises de 
conteúdo (caracteres, espaços, palavras, linhas, páginas, repetições etc.). Após esse processo de busca e quantificação, procedeu-se, também, à quantificação do número total de palavras, assim como do número de páginas das DFAC divulgadas pelas companhias. Essas informações foram utilizadas como denominadores do número de palavras e expressões encontradas relativas à divulgação social e ambiental, a fim de quantificar o disclosure. Dessa forma, a quantificação dos índices consistiu no somatório geral de palavras e expressões-chaves pesquisadas relativizadas (i) pelo número de total de palavras e (ii) pelo número de páginas das DFAC. Assim, o presente estudo utiliza seis índices de mensuração do disclosure ambiental e social, conforme Tabela 4. Essa divisão do total de palavras buscadas pelo número de páginas e palavras foi adotada, por exemplo, por Muslu et al. (2015) nos Estados Uunidos, por Marquezan et al. (2015) e Viana Junior e Crisóstomo (2016) no Brasil e por Gamerschlag, Möller e Verbeeten (2011) na Alemanha.

Tabela 4 - Índices de disclosure ambiental e social

\begin{tabular}{|c|c|c|}
\hline Índices & Relativização pelo número de páginas & $\begin{array}{c}\text { Relativização pelo número total de pala- } \\
\text { vras }\end{array}$ \\
\hline \multirow{2}{*}{$\begin{array}{l}\text { Índice de } \\
\text { disclosure am- } \\
\text { biental }\end{array}$} & $\left(\begin{array}{c}\text { Número total de palavras } \\
\text { ambientais pesquisadas }\end{array}\right)$ & \multirow{2}{*}{ IDAplvra $=\frac{\left(\begin{array}{c}\text { ambient ais pesquisadas } \\
\text { do documento }\end{array}\right.}{\text { dotal de palavras }}$} \\
\hline & IDApag $=\frac{\left(\begin{array}{c}\text { Número de páginas } \\
\text { do documento }\end{array}\right)}{}$ & \\
\hline \multirow{2}{*}{$\begin{array}{l}\text { Índice de dis- } \\
\text { closure social }\end{array}$} & $-\frac{\left(\begin{array}{c}\text { Número total de palavras } \\
\text { sociais pesquisadas }\end{array}\right)}{\text { sols }}$ & \multirow{2}{*}{ IDSplvra $=\frac{\left(\begin{array}{c}\text { Número total de palavras } \\
\text { sociais pesquisadas }\end{array}\right)}{\left(\begin{array}{c}\text { Número total de palavras } \\
\text { do documento }\end{array}\right)}$} \\
\hline & TDSpag $=\left(\begin{array}{c}\text { Número de páginas } \\
\text { do documento }\end{array}\right)$ & \\
\hline \multirow{2}{*}{$\begin{array}{l}\text { Índice de dis- } \\
\text { closure socio- } \\
\text { ambiental }\end{array}$} & $\left(\begin{array}{c}\text { Número total de } \\
\text { palavras ambientais } \\
\text { e sociais pesquisadas }\end{array}\right)$ & \multirow{2}{*}{ IDSAplvra $=\frac{\left(\begin{array}{c}\text { Número total de } \\
\text { palavras ambientais } \\
\text { e sociais pesquisadas }\end{array}\right)}{\left(\begin{array}{c}\text { Número total de palavras } \\
\text { do documento }\end{array}\right)}$} \\
\hline & $\left(\begin{array}{c}\text { Número de páginas } \\
\text { do documento }\end{array}\right)$ & \\
\hline
\end{tabular}

Fonte: elaborada pelos autores.

\subsection{Procedimentos estatísticos}

Foi realizado um detalhado estudo descritivo dos seis índices propostos para a quantificação do disclosure socioambiental, segregando-se as análises por setor de impacto (Baixo Impacto, Médio Impacto, Alto Impacto e Sem Impacto), conforme Lei n. 10.165/2000. Adicionalmente, utilizou-se teste de comparação de médias dos valores dos índices entre os vários grupos de empresas de acordo com o grau de impacto ambiental: Análise de Variância (Anova), Teste Tukey - Honestly Significant Difference (HSD) - e Teste de Kruskal-Wallis. A utilização de testes paramétricos e não paramétricos provê mais robustez às análises.

Dessa forma, a comparação de média dos índices de disclosure ambiental e social entre diferentes grupos de empresas permite avaliar se as populações (grupos de empresas) são, de fato, distintas e por isso apresentam valores diferentes de indicadores de disclosure, havendo, assim, algum fator que ocasione ou justifique tal distinção como hipotetizado. Por outro lado, pode-se verificar que não há distinção entre as médias dos indicadores, que são, na verdade, equivalentes, assim como o nível de disclosure das empresas dos grupos comparados. Para a realização dos testes, foram utilizados os softwares Statistical Package for Social Science (SPSS), versão 21.0, e Data Analysis and Statistical Software (STATA), versão 14.0. 


\section{APRESENTAÇÃO DE RESULTADOS}

\subsection{Resultados}

A Tabela 5 contempla as estatísticas descritivas dos seis índices propostos neste estudo para quantificação do disclosure socioambiental, segregando as observações por setor de impacto ambiental. Dessa maneira, considerando-se primeiramente os índices que se consubstanciaram pela relativização das palavras/expressões encontradas pelo número de páginas das Demonstrações Financeiras (IDA_pag, IDS_pag e IDSA_pag), observa-se que a média dos índices IDA_pag e IDSA_pag no setor de Alto Impacto é superior quando comparada aos demais setores, alinhando-se à hipótese levantada neste estudo de que empresas pertencentes a setores mais altamente impactantes iriam divulgar mais informações socioambientais do que as demais. Destaca-se, também, ainda com base nos índices relativizados pelo número de páginas dos demonstrativos contábeis, coeficientes de variação maiores para as empresas de setores de Alto Impacto quando comparados às empresas dos setores de Médio e Baixo Impacto, indicando, assim, uma heterogeneidade maior do disclosure por parte das empresas mais altamente impactantes.

Tabela 5 - Estatística descritiva por Setor de Impacto conforme Lei n.o 10.165/2000

\begin{tabular}{|c|c|c|c|c|c|c|}
\hline \multirow[b]{2}{*}{ SEM IMPACTO } & \multicolumn{3}{|c|}{ Número de Páginas } & \multicolumn{3}{|c|}{ Número de Palavras } \\
\hline & Ambiental & Social & Socioambiental & Ambiental & Social & Socioambiental \\
\hline $\mathrm{N}$ & 782 & 782 & 782 & 782 & 782 & 782 \\
\hline Média & 0,0425 & 0,0490 & 0,0915 & 0,0002 & 0,0003 & 0,0005 \\
\hline Desvio-padrão & 0,0833 & 0,0663 & 0,1129 & 0,0005 & 0,0004 & 0,0007 \\
\hline $\begin{array}{l}\text { Coeficiente de } \\
\text { Variação }\end{array}$ & 1,9572 & 1,3528 & 1,2339 & 2,0303 & 1,3808 & 1,2743 \\
\hline Mediana & 0,0085 & 0,0276 & 0,0536 & 0,0001 & 0,0002 & 0,0003 \\
\hline Mínimo & 0,0000 & 0,0000 & 0,0000 & 0,0000 & 0,0000 & 0,0000 \\
\hline Máximo & 0,6663 & 0,5692 & 0,9174 & 0,0043 & 0,0034 & 0,0059 \\
\hline BAIXO IMPACTO & Ambiental & Social & Socioambiental & Ambiental & Social & Socioambiental \\
\hline $\mathrm{N}$ & 20 & 20 & 20 & 20 & 20 & 20 \\
\hline Média & 0,0396 & 0,0283 & 0,0679 & 0,0002 & 0,0002 & 0,0004 \\
\hline Desvio-padrão & 0,0308 & 0,0205 & 0,0415 & 0,0002 & 0,0001 & 0,0003 \\
\hline $\begin{array}{l}\text { Coeficiente de } \\
\text { Variação }\end{array}$ & 0,7765 & 0,7262 & 0,6112 & 0,7720 & 0,7326 & 0,6122 \\
\hline Mediana & 0,0461 & 0,0303 & 0,0520 & 0,0003 & 0,0002 & 0,0003 \\
\hline Mínimo & 0,0000 & 0,0000 & 0,0128 & 0,0000 & 0,0000 & 0,0001 \\
\hline Máximo & 0,0995 & 0,0543 & 0,1538 & 0,0006 & 0,0003 & 0,0009 \\
\hline $\begin{array}{l}\text { MÉDIO IMPAC- } \\
\text { TO } \\
\end{array}$ & Ambiental & Social & Socioambiental & Ambiental & Social & Socioambiental \\
\hline $\mathrm{N}$ & 632 & 632 & 632 & 632 & 632 & 632 \\
\hline Média & 0,0692 & 0,0777 & 0,1469 & 0,0004 & 0,0005 & 0,0009 \\
\hline Desvio-padrão & 0,0933 & 0,0756 & 0,1384 & 0,0006 & 0,0004 & 0,0008 \\
\hline $\begin{array}{l}\text { Coeficiente de } \\
\text { Variação }\end{array}$ & 1,3484 & 0,9724 & 0,9425 & 1,3844 & 0,9617 & 0,9592 \\
\hline Mediana & 0,0373 & 0,0534 & 0,1123 & 0,0002 & 0,0003 & 0,0008 \\
\hline Mínimo & 0,0000 & 0,0000 & 0,0000 & 0,0000 & 0,0000 & 0,0000 \\
\hline Máximo & 0,6023 & 0,5720 & 1,0118 & 0,0037 & 0,0035 & 0,0062 \\
\hline ALTO IMPACTO & Ambiental & Social & Socioambiental & Ambiental & Social & Socioambiental \\
\hline $\mathrm{N}$ & 237 & 237 & 237 & 237 & 237 & 237 \\
\hline Média & 0,0857 & 0,0642 & 0,1498 & 0,0005 & 0,0004 & 0,0009 \\
\hline
\end{tabular}




\begin{tabular}{ccccccc}
$\begin{array}{c}\text { Desvio-padrão } \\
\text { Coeficiente de } \\
\text { Variação }\end{array}$ & 0,1185 & 0,0680 & 0,1556 & 0,0007 & 0,0004 & 0,0010 \\
Mediana & 0,0440 & 0,0454 & 0,0995 & 0,0003 & 0,0003 & 0,0006 \\
Mínimo & 0,0000 & 0,0000 & 0,0000 & 0,0000 & 0,0000 & 0,0000 \\
Máximo & 0,5897 & 0,5454 & 0,9190 & 0,0039 & 0,0034 & 0,0056 \\
\hline TOTAL & Ambiental & Social & Socioambiental & Ambiental & Social & Socioambiental \\
\hline N & 1.671 & 1.671 & 1.671 & 1.671 & 1.671 & 1.671 \\
Média & 0,0587 & 0,0618 & 0,1204 & 0,0003 & 0,0004 & 0,0007 \\
$\begin{array}{c}\text { Desvio-padrão } \\
\text { Coeficiente de }\end{array}$ & 0,0938 & 0,0711 & 0,1321 & 0,0006 & 0,0004 & 0,0008 \\
Variação & 1,5978 & 1,1514 & 1,0970 & 1,6395 & 1,1590 & 1,1225 \\
Mediana & 0,0260 & 0,0390 & 0,0772 & 0,0001 & 0,0002 & 0,0004 \\
Mínimo & 0,0000 & 0,0000 & 0,0000 & 0,0000 & 0,0000 & 0,0000 \\
Máximo & 0,6663 & 0,5720 & 1,0118 & 0,0043 & 0,0035 & 0,0062 \\
\hline
\end{tabular}

Fonte: elaborada pelos autores.

Alinhado ao exposto, ainda com base na Tabela 5, mas tendo em vista os índices IDA_plvra, IDS_plvra e IDSA_plvra (calculados com base na relativização das palavras/expressões buscadas pelo número total de palavras das Demonstrações Financeiras), observa-se em média índices de disclosure superiores por parte das empresas de Alto Impacto quando comparadas às empresas de Médio e Baixo Impacto. Desse modo, assim como para os índices calculados com base no número de páginas dos documentos, observam-se indícios de níveis de evidenciação socioambiental mais elevados por parte de empresas pertencentes a setores de maior impacto ambiental, conforme a Lei n.o 10.165/2000.

Ainda pelo exposto na Tabela 5, destaque-se o fato de, em todos níveis de impacto analisados (alto, médio, baixo e sem impacto), terem sido encontradas empresas que não usaram nenhuma das 77 palavras ligadas à divulgação ambiental e social, sinalizando relutância por práticas desse tipo de disclosure, relutância essa que independe do potencial de poluição de suas atividades.

Tais resultados indicam que, de fato, empresas classificadas pela PNMA como potencialmente poluidoras apresentam um nível mais elevado de evidenciação de informações socioambientais em suas demonstrações financeiras quando comparadas às demais empresas, corroborando as análises realizadas por alguns estudos nacionais (CRISÓSTOMO; SOUZA; PARENTE, 2012; MARQUEZAN et al., 2015; VIANA JUNIOR; CRISÓSTOMO, 2016).

Aprofundando a análise, realizou-se a comparação de médias por análise de variância (Anova) entre as médias dos grupos de empresas pertencentes aos setores de Alto Impacto, Médio Impacto, Baixo Impacto e Sem Impacto, assim como o teste não paramétrico de Kruskal -Wallis. Os resultados são apresentados na Tabela 6. 
NÍVEL DE DISCLOSURE SOCIOAMBIENTAL:

UMA ANÁLISE COMPARATIVA ENTRE EMPRESAS BRASILEIRAS

DE ACORDO COM O POTENCIAL DE AGRESSÃO AO MEIO AMBIENTE

Tabela 6 - Análise de Variância (Anova) e Teste de Kruskal-Wallis entre os setores de impacto

\begin{tabular}{|c|c|c|c|c|c|c|c|c|c|}
\hline $\begin{array}{l}\text { NÚMERO DE } \\
\text { PÁGINAS }\end{array}$ & \multicolumn{3}{|c|}{ IDA_pag } & \multicolumn{3}{|c|}{ IDS_pag } & \multicolumn{3}{|c|}{ IDSA_pag } \\
\hline \multirow[t]{2}{*}{ Setor } & \multirow{2}{*}{ Média } & $\begin{array}{l}\text { Kruskal } \\
\text { Wallis }\end{array}$ & Anova & \multirow[t]{2}{*}{ Média } & $\begin{array}{l}\text { Kruskal } \\
\text { Wallis }\end{array}$ & Anova & \multirow{2}{*}{ Média } & $\begin{array}{l}\text { Kruskal } \\
\text { Wallis }\end{array}$ & Anova \\
\hline & & \multicolumn{2}{|c|}{$\mathrm{p}$-value } & & \multicolumn{2}{|c|}{$\mathrm{p}$-value } & & \multicolumn{2}{|c|}{$\mathrm{p}$-value } \\
\hline Sem Impacto & 0,0426 & \multirow{4}{*}{0,000} & \multirow{4}{*}{0,000} & 0,0490 & \multirow{4}{*}{0,000} & \multirow{4}{*}{0,000} & 0,0915 & \multirow{4}{*}{0,000} & \multirow{4}{*}{0,000} \\
\hline Baixo Impacto & 0,0396 & & & 0,0283 & & & 0,0679 & & \\
\hline $\begin{array}{l}\text { Médio Im- } \\
\text { pacto }\end{array}$ & 0,0692 & & & 0,0777 & & & 0,1469 & & \\
\hline Alto Impacto & 0,0857 & & & 0,0642 & & & 0,1498 & & \\
\hline $\begin{array}{l}\text { TOTAL PALA- } \\
\text { VRAS }\end{array}$ & \multicolumn{3}{|c|}{ IDA_plvra } & \multicolumn{3}{|c|}{ IDS_plvra } & \multicolumn{3}{|c|}{ IDSA_plvra } \\
\hline \multirow{2}{*}{ Setor } & \multirow{2}{*}{ Média } & $\begin{array}{l}\text { Kruskal } \\
\text { Wallis }\end{array}$ & Anova & \multirow{2}{*}{ Média } & $\begin{array}{l}\text { Kruskal } \\
\text { Wallis }\end{array}$ & Anova & \multirow{2}{*}{ Média } & $\begin{array}{l}\text { Kruskal } \\
\text { Wallis }\end{array}$ & Anova \\
\hline & & \multicolumn{2}{|c|}{$\mathrm{p}$-value } & & \multicolumn{2}{|c|}{$\mathrm{p}$-value } & & \multicolumn{2}{|c|}{$\mathrm{p}$-value } \\
\hline Sem Impacto & 0,0003 & \multirow{4}{*}{0,000} & \multirow{4}{*}{0,000} & 0,0003 & \multirow{4}{*}{0,000} & \multirow{4}{*}{0,000} & 0,0005 & \multirow{4}{*}{0,000} & \multirow{4}{*}{0,000} \\
\hline Baixo Impacto & 0,0002 & & & 0,0002 & & & 0,0004 & & \\
\hline $\begin{array}{l}\text { Médio Im- } \\
\text { pacto }\end{array}$ & 0,0004 & & & 0,0005 & & & 0,0009 & & \\
\hline Alto Impacto & 0,0005 & & & 0,0004 & & & 0,0010 & & \\
\hline
\end{tabular}

Notas: Sem Impacto ( $\mathrm{N}=782$ ); Baixo Impacto ( $\mathrm{N}=20)$; Médio Impacto ( $\mathrm{N}=632$ ); Alto Impacto ( $\mathrm{N}=237)$.

Fonte: elaborada pelos autores.

Conforme dados exibidos na Tabela 6, pode-se observar que há diferença estatisticamente significante entre as médias dos quatro grupos de empresas no que concerne ao grau de impacto ambiental. Nota-se, assim, que as empresas de setores considerados como de alto impacto ambiental, de fato, tendem a apresentar nível mais elevado de disclosure ambiental (IDA_pag e IDA_plvra) e socioambiental (IDSA_pag e IDSA_plvra).

Por sua vez, empresas consideradas como de médio impacto ambiental apresentaram uma pequena superioridade nos indicadores sociais (IDS_pag e IDS_plvra) em relação às empresas de alto impacto. Outro aspecto que merece atenção é a tênue fronteira entre as empresas de baixo impacto e as empresas não previstas pela Lei n. $10.165 / 2000$. Na verdade, todos os indicadores das empresas consideradas como de baixo impacto ambiental foram inferiores àqueles das empresas não consideradas como impactantes ambientalmente. $O$ reduzido número de observações de empresas de baixo impacto pode, entretanto, influenciar nesse resultado.

Análises mais detalhados de comparação entre todos os setores, realizadas por meio do Teste Tukey HDS, aprofundam essa análise, como pode ser visto na Tabela 7.

Tabela 7 - Teste de Tukey HSD: comparações múltiplas de médias

\begin{tabular}{c|c|c|c|c|c|c|c}
\hline \multicolumn{2}{c|}{ NÚMERO DE PÁGINAS } & \multicolumn{2}{c|}{ IDA_pag } & \multicolumn{2}{c}{ IDS_pag } & \multicolumn{2}{c}{ IDSA_pag } \\
\hline$(\mathrm{A})$ & $(\mathrm{B})$ & $(\mathrm{A})-(\mathrm{B})$ & $\mathrm{p}$-value & $(\mathrm{A})-(\mathrm{B})$ & $\mathrm{p}$-value & $(\mathrm{A})-(\mathrm{B})$ & $\mathrm{p}$-value \\
\hline Baixo Impacto & Sem Impacto & $-0,0029$ & 0,999 & $-0,0207$ & 0,557 & $-0,0236$ & 0,851 \\
\hline Médio Impacto & Sem Impacto & 0,0266 & 0,000 & 0,0287 & 0,000 & 0,0554 & 0,000 \\
\hline Alto Impacto & Sem Impacto & 0,0431 & 0,000 & 0,0152 & 0,018 & 0,0583 & 0,000 \\
\hline Médio Impacto & Baixo Impacto & 0,0295 & 0,494 & 0,0494 & 0,010 & 0,0790 & 0,036 \\
\hline Alto Impacto & Baixo Impacto & 0,0460 & 0,141 & 0,0359 & 0,121 & 0,0819 & 0,033 \\
\hline Alto Impacto & Médio Impacto & 0,0165 & 0,089 & $-0,0135$ & 0,053 & 0,0029 & 0,991 \\
\hline
\end{tabular}




\begin{tabular}{c|c|c|c|c|c|c|c}
\hline \multicolumn{2}{c|}{ TOTAL PALAVRAS } & \multicolumn{2}{c|}{ IDA_plvra } & \multicolumn{2}{c}{ IDS_plvra } & \multicolumn{2}{c}{ IDSA_plvra } \\
\hline$(\mathrm{A})$ & $(\mathrm{B})$ & $(\mathrm{A})-(\mathrm{B})$ & $\mathrm{p}$-value & $(\mathrm{A})-(\mathrm{B})$ & $\mathrm{p}$-value & $(\mathrm{A})-(\mathrm{B})$ & $\mathrm{p}$-value \\
\hline Baixo Impacto & Sem Impacto & $-0,0000$ & 1,000 & $-0,0001$ & 0,590 & $-0,0001$ & 0,881 \\
\hline Médio Impacto & Sem Impacto & 0,0002 & 0,000 & 0,0002 & 0,000 & 0,0003 & 0,000 \\
\hline Alto Impacto & Sem Impacto & 0,0003 & 0,000 & 0,0001 & 0,011 & 0,0004 & 0,000 \\
\hline Médio Impacto & Baixo Impacto & 0,0002 & 0,527 & 0,0003 & 0,012 & 0,0005 & 0,047 \\
\hline Alto Impacto & Baixo Impacto & 0,0003 & 0,165 & 0,0002 & 0,123 & 0,0005 & 0,040 \\
\hline Alto Impacto & Médio Impacto & 0,0001 & 0,106 & $-0,0001$ & 0,087 & 0,0001 & 0,981 \\
\hline Fonte: elaborada pelos autores.
\end{tabular}

Os resultados indicam que, de fato, não há diferença estatística entre a média de indicadores das empresas de baixo impacto ambiental e aquelas não previstas na Lei (Tabela 7). Por outro lado, verifica-se a superioridade de todos os indicadores entre as empresas consideradas como de médio e alto impacto ambiental comparativamente àquelas de setores não previstos na Lei n.o 10.165/2000.

Este trabalho expande, assim, a perspectiva de estudos anteriores no Brasil ao apresentar resultados para um contingente mais relevante de empresas atuantes em distintos setores da economia e analisar um período temporal mais amplo. Nesse sentido, os achados atuais corroboram os resultados de Viana Junior e Crisóstomo (2016), que encontraram evidência semelhante ao investigarem o nível de divulgação ambiental de 114 empresas classificadas como de alto, médio e baixo impacto ambiental ao longo dos anos de 2012 a 2014.

Portanto, ao expandir o horizonte amostral - com 1.671 observações - e a janela temporal de análise (2010 a 2014), o presente estudo reitera a discussão de que a classificação das atividades desenvolvidas pelas organizações como sendo de alto, médio e baixo impacto, proposta pela PNMA, parece surtir efeito nas organizações, no sentido de pressionar estas a adotarem níveis mais elevados de preocupação socioambiental com reflexos no grau de divulgação das informações. Nesse sentido, parece válido o argumento de que empresas taxadas pela legislação como mais altamente impactantes divulgam informes socioambientais mais completos, seja pela demanda de um coletivo de stakeholders mais exigentes, seja por uma preocupação mais elevada com essas questões, indicando um possível efeito enforcement, como a literatura tem sugerido (CRISÓSTOMO; SOUZA; PARENTE, 2012, PEDERSEN, 2013).

\subsection{Discussão}

Algumas correntes teóricas podem explicar o conjunto de resultados que demonstram que empresas de setores considerados como desenvolvedores de atividades com mais elevado potencial de impacto ambiental tendem a adotar mais medidas de prevenção a sinistros ambientais, sendo, assim, mais propensas a apresentar mais alto nível de disclosure de informações de cunho socioambiental.

Sob o enfoque da teoria dos stakeholders, o coletivo de stakeholders que interage com a empresa tende a demandar mais responsabilidade social e ambiental das organizações com mais propensão a agredir o meio ambiente em função das consequências negativas que sua ação pode trazer ao meio ambiente e à sociedade. Nesse sentido, empresas com maior potencial de impacto ao meio ambiente tenderiam a ser mais sensíveis à pressão de stakeholders, uma vez que a relação empresa-meio ambiente tem cada dia mais visibilidade e que a responsabilidade ambiental ocupa a "ordem do dia" (FREEMAN; PHILLIPS, 2002). Dessa forma, o mais alto grau de divulgação socioambiental de empresas de maior impacto segundo a legislação ambiental pode ser uma resposta à pressão dos stakeholders, o que, por sua vez, pode somar-se à busca 
por legitimação das empresas, que encontram em níveis mais elevados de disclosure uma forma de melhor transmitir aos stakeholders seu alto grau de preocupação com as questões socioambientais (DIAS FILHO, 2012; SUCHMAN, 1995), contribuindo, assim, para melhoria de imagem e reputação corporativa.

Por outro lado, mas não de forma excludente, o mais alto grau de divulgação socioambiental pode também ser consequência de um eventual efeito regulatório, ou enforcement, advindo da explicitação para a sociedade das empresas dos setores da economia com elevado potencial de agressão ao meio ambiente, bem como da determinação de mais enfática fiscalização à atuação dessas empresas, o que faz com que tenham uma maior preocupação em adotar sistemas de controle e monitoramento ambiental dotados de modernos mecanismos de prevenção a sinistros, o que usualmente envolve constante investimento em inovação tecnológica (GLICKSMAN; MARKED; MONTELEONI, 2017).

Assim, as empresas de setores mais potencialmente agressivos ao meio ambiente são obrigadas a enviar o RAPP ao Ibama, o que já as obriga a elaborar um relatório específico sobre a sua relação com o meio ambiente. Esses fatores institucionais tendem a contribuir para que a empresa elabore e divulgue relatórios de sustentabilidade mais completos e abrangentes que contemplem toda a informação relativa a tais sistemas de controle (VIANA JUNIOR; CRISÓSTOMO, 2016).

A possibilidade de um efeito regulatório no Brasil em função do aprimoramento da legislação que compõe a PNMA confirma o efeito regulatório quanto às questões ambientais proposto em distintos mercados, efeito que tem sido percebido em outras pesquisas, ainda que os resultados não sejam conclusivos devido à complexidade da questão (PEDERSEN, 2013). Há, também, resultados que apontam um efeito da ideologia política do governo local como um fator moderador da intensidade da efetividade da legislação ambiental, como no caso sueco (SJÖBERG, 2016). Esse aspecto político e a questão local no que concerne a políticas com mais amplo espectro geográfico constituem um potencial estudo futuro.

\section{CONCLUSÕES}

Este trabalho fez uma análise do nível de disclosure ambiental, social e socioambiental praticado por empresas brasileiras cujas atividades são identificadas como de alto, médio e baixo impacto ambiental, conforme classificação proposta pela PNMA (respaldada na Lei n.. 10.165 de 2000). Por meio de análise léxica das DFAC das firmas, com a contagem de 43 palavras e expressões-chaves relacionadas ao disclosure ambiental, e 34 palavras/expressões pertinentes à divulgação social, os resultados apresentaram fortes indícios de um maior nível de divulgação de caráter ambiental, social e socioambiental por parte das empresas classificadas como de alto impacto ambiental quando comparado às demais companhias.

O mais elevado nível de divulgação socioambiental pode dever-se a uma ação socioambiental mais efetiva, aliada a uma mais alta cobrança por parte dos stakeholders. A esse respeito, cabe salientar, ainda, que a obrigação da elaboração e do envio do RAPP ao Ibama por parte das empresas classificadas pela Lei n. 10.165/2000 também parece ter efeito sobre os níveis de disclosure socioambiental das firmas nas DFAC. Uma vez que são obrigadas a elaborarem informações para que atendam aos requisitos do RAPP, é possível que muitos dos dados ali divulgados facilitem o processo de disclosure socioambiental das empresas nas DFAC. Dessa forma, a Lei n. 0 10.165/2000 exerceria um papel impulsionador sobre as empresas que poderia se refletir em outros meios de divulgação.

Esses resultados de mais elevado grau de divulgação de informação socioambiental de empresas de setores considerados com maior potencial de impacto ambiental encontram am- 
paro no enfoque da teoria dos stakeholders, assim como na proposição de um possível efeito regulatório, ou enforcement. Sob o enfoque da teoria dos stakeholders, preconiza-se que stakeholders são capazes de pressionar a empresa no sentido de ter uma atuação socioambiental mais responsável. Dessa forma, a empresa procurará demonstrar o mais elevado nível de preocupação socioambiental, elaborando, inclusive, demonstrações financeiras com mais aspectos voltados à sustentabilidade, o que pode conferir mais visibilidade positiva e auxiliar a legitimar sua atuação. O possível efeito regulatório também pode explicar este mais elevado grau de divulgação socioambiental por parte de empresas com maior risco de agressão ao meio ambiente, uma vez que a legislação ambiental brasileira, apesar de ainda incipiente se comparada à legislação de países desenvolvidos, tem apresentado avanços e criado mecanismos específicos de controle de empresas destes setores mais potencialmente agressivos ao meio ambiente, prevendo determinadas obrigações quanto à fiscalização e divulgação de informação.

Os resultados deste trabalho podem ser vistos como uma contribuição para a literatura nacional acerca do disclosure voluntário socioambiental e do entorno legal e institucional. Nesse sentido, espera-se que o estudo venha a auxiliar na gestão empresarial sobre a divulgação de informações de cunho socioambiental. Nesse espectro, vislumbra-se, também, a continuidade deste estudo com a replicação dos índices aqui propostos em cenários temporais mais amplos, ou mesmo utilizando-se grupos amostrais diferentes do aqui discutido. Outra perspectiva de trabalho é a busca de fatores que contribuem para o mais elevado grau de divulgação socioambiental.

\section{REFERÊNCIAS}

AGRA FILHO, S. S. Conflitos ambientais e os instrumentos da Política Nacional de Meio Ambiente. Revista Eletrônica de Gestão de Negócios, v. 4, n. 2, p. 127-140, 2008.

AHMAD, Z.; SALLET, H.; MOHAMMAD, J. Determinants of environmental reporting in Malaysia. International Journal of Business Studies, v. 11, n. 1, p. 69-90, 2003.

BARDIN, L. Análise de Conteúdo. Tradução de Luiz Antero Reto e Augusto Pinheiro. Lisboa: Ed, v. 70, 1977.

BARTON, S. L.; HILL, S. C.; SUNDARAM, S. An Empirical Test of Stakeholder Theory Predictions of Capital Structure. Financial Management, v. 18, n. 1, p. 36-44, 1989.

BOESSO, G.; KUMAR, K. Drivers of corporate voluntary disclosure: A framework and empirical evidence from Italy and the United States. Accounting, Auditing \& Accountability, v. 20, n. 2, p. 269-296, 2007.
BOMFIM, E. T.; TEIXEIRA, W. S.; MONTE, P. A. Relação entre o disclosure da sustentabilidade com a governança corporativa: um estudo nas empresas listadas no Ibrx-100. Sociedade, Contabilidade e Gestão, v. 10, n. 1, p. 6-28, 2015.

BORGES, L. A. C.; REZENDE, J. L. P.; PEREIRA, J. A. A. Evolução da legislação ambiental no Brasil. Revista em Agronegócios e Meio Ambiente, $v$. 2, n. 3, p. 447-466, 2009.

BRAGA, C.; SILVA, P. P.; SANTOS, A. Environmental disclosure in the Brazilian electricity sector. International Journal of Innovation and Sustainable Development, $v$. 8, n. 1, p. 37-52, 2014.

BRAMMER, S.; PAVELIN, S. Factors influencing the quality of Corporate Environmental Disclosure. Business Strategy and the Environment, v. 17, n. 1, p. 120-136, 2008.

BURCHELL, S.; CLUBB, C.; HOPWOOD, A.; HUGHIES, J; NAHAPIET, J. The roles of Accounting in organizations and society. Accounting, Organizations and Society, v. 5, n. 1, p. 5-27, 1980. 
BRASIL. Constituição (1988). Constituição da República Federativa do Brasil. Brasília, DF: Senado, 1988.

BRASIL. Lei no 6.938, de 31 de agosto de 1981. Dispõe sobre a Política Nacional do Meio Ambiente, seus fins e mecanismos de formulação e aplicação, e dá outras providências. Diário Oficial da União. Brasília, 31 de agosto de 1981. Disponível em: <http:// www.planalto.gov.br/ccivil_03/leis/L6938. htm>. Acesso em: 21 jul. 2016.

BRASIL. Lei no 10.165, de 27 de dezembro de 2000. Altera a lei $n=6.938$, de 31 de agosto de 1981, que dispõe sobre a Política Nacional do Meio Ambiente, seus fins e mecanismos de formulação e aplicação, e dá outras providências. Diário Oficial da União. Brasília, 27 de dezembro de 2000. Disponível em: <http://www.planalto.gov.br/ccivil_03/Leis/ L10165.htm>. Acesso em: 17 ago. 2016.

CARDOSO, V. I. C.; DE LUCA, M. M. M.; AQUINO, T. A. Práticas de disclosure econômico e socioambiental nas maiores empresas do Brasil. Revista de Administração da UFSM, v. 9, n. 1, p. 157-172, 2016.

CORMIER, D.; GORDON, I. M. An examination of social and environmental reporting strategies. Accounting, Auditing \& Accountability, v. 14, n. 5, p. 587-617, 2001.

CRISÓSTOMO, V. L.; SOUZA, J. L.; PARENTE, P. H. N. Possível efeito regulatório na responsabilidade socioambiental da empresa brasileira em função da Lei no 10.165/2000. Revista de Gestão Social e Ambiental, v. 6, n. 3, p. 154-167, 2012.

CRUZ, C. F.; MARQUES, A. L.; FERREIRA, A. C. $S$. Informações ambientais na contabilidade pública: reconhecimento de sua importância para a sustentabilidade. Sociedade, Contabilidade e Gestão, v. 4, n. 2, p. 7-23, 2010.

DEEGAN, C.; GORDON, B. A study of the environmental disclosure practices of Australian corporations. Accounting and Business Research, v. 26, n. 3, p. 187-199, 1996.

DIAS FILHO, J. M. A Pesquisa Qualitativa sob a Perspectiva da Teoria da Legitimidade: uma alternativa para explicar e predizer políticas de evidenciação contábil. Interface, v. 9, n. 1, p. 73-86, 2012.

ECONOMATICA. Padrão de classificação setorial - 2017. Disponível em: < http:// economatica.com/support/manual/pt_javas/ DCF/Medias_setoriais_historicas.htm $>$. Acesso em 15 ago 2017.

FERNANDES, S. M. Os efeitos do disclosure ambiental negativo involuntário: um estudo de evento nas companhias brasileiras com alto ínidice de poluição. Revista de Contabilidade e Organizações, v. 7, n. 17, p. 59-72, 2013.

FONTENELLE, M. Aspectos da Política Nacional do Meio Ambiente: um estudo de impacto ambiental como instrumento preventivo da gestão ambiental. Revista da Faculdade de Direito de Campos, v. 5, n. 5, p. 271-302, 2004.

FREEMAN, R. E.; PHILLIPS, R. A. Stakeholder Theory: a libertarian defense. Business Ethics Quarterly, v. 12, n. 3, p. 331-349, 2002.

FREITAS, H.; MOSCAROLA, J. Da observação à decisão: métodos de pesquisa e de análise quantitativa e qualitativa de dados. Revista de Administração de Empresas, v. 1, n. 1, p. 2-30, 2002.

FREITAS, H.; JANISSEK, R. Análise léxica e análise de conteúdo: técnicas complementares, seqüenciais e recorrentes para exploração de dados qualitativos. Porto Alegre: Sagra Luzzatto, 2000.

FROST, G. R.; WILMSHURST, T. D. The adoption of environmental-related management accounting: an analysis of corporate environmental sensitivity. Accounting Forum, v. 24, n. 4, p. 344-365, 2000. 
GAMERSCHLAG, R., MÖLLER, K., VERBEETEN, F. Determinants of voluntary CSR disclosure: empirical evidence from Germany. Review of Managerial Science, v. 5, n. 2-3, p. 233-262, 2011.

GLICKSMAN, R. L.; MARKED, D. L.; MONTELEONI, C. Technological Innovation, Data Analytics, and Environmental Enforcement. Ecology Law Quarterly, v. 44, n. 1, p. 41-88, 2017.

GRI. G4 Sustainability Reporting Guidelines - 2016. Disponível em: < https://www. globalreporting.org/resourcelibrary/GRIG4Part1-Reporting-Principles-and-StandardDisclosures.pdf>. Acesso em 15 ago 2017.

HARTE, G., \& OWEN, D. Environmental disclosure in the Annual Reports of British companies: a research note. Accounting, Auditing \& Accountability, v. 4, n. 3, p. 51-61, 1991.

HUANG, C. L.; KUNG, F. H. Drivers of Environmental Disclosure and Stakeholder Expectation: Evidence from Taiwan. Journal of Business Ethics, v. 96, n. 3, p. 435-451, 2010.

LAMPE, M. Mediation as an ethical adjunct of Stakeholder Theory. Journal of Business Ethics, v. 31, n. 1, p. 165-173, 2001.

LIU, X.; ANBUMOZHI, V. Determinant factors of corporate environmental information disclosure: an empirical study of Chinese listed companies. Journal of Cleaner Production, $v$. 17, n. 6, p. 593-600, 2009.

MAPURUNGA, P. V. R.; LIMA, B. C. C.; HOLANDA, A. P. Disclosure social e isomorfismo nas empresas listadas no índice de sustentabilidade empresarial. Revista de Administração da UFSM, v. 8, n. 2, p. 267-281, 2015.

MARQUEZAN, L. H. F.; SEIBERT, R. M.; BARTZ, D.; BARBOSA, M. A. G.; ALVES, T. W. Análise dos determinantes do disclosure verde em relatórios anuais de empresas listadas na BM\&FBovespa. Contabilidade, Gestão e Governança, v. 18, n. 1, p. 127-150, 2015.
MURCIA, F. D. R.; FÁVERO, L. P. L.; ROVER, S.; LIMA, G. A. S. F.; LIMA, I. Disclosure Verde nas demonstrações contábeis: características da informação ambiental e possíveis explicações para a divulgação voluntária. Revista Contabilidade, Gestão e Governança, v. 11, n. 1-2, p. 260-278, 2008.

MUSLU, V.; RADHAKRISHNAN, S.; SUBRAMANYAM, K. R.; LIM, D. ForwardLooking MD\&A disclosures and the information environment. Management Science, v. 61, n. 5, p. 931-948, 2015.

NAICS. North American Industry Classification System - 2017. Disponível em: <https://www. census.gov/eos/www/naics/>. Acesso em 15 ago 2017.

OLIVEIRA, I. A. F.; COELHO, A. C. D. Impacto da divulgação obrigatória da dva: evidência em indicadores financeiros. Revista Evidenciação Contábil \& Finanças, v. 2, n.3, p. 41-55, 2014.

PEDERSEN, O. W. Environmental Enforcement Undertakings and Possible Implications: Responsive, Smarter or Rent Seeking? The Modern Law Review, v. 76, n. 2, p. 319-345, 2013.

PRESTON, L. E. Analyzing corporate social performance-methods and results. Journal of Contemporary Business, v. 7, n. 1, p. 135-150, 1978.

PINHEIRO, V. A. A.; BOSCOV, C. P. Análise de informações por segmento das empresas premiadas pelo troféu transparência ANEFAC/ FIPECAFI/SERASA 2013. ConTexto, v. 15, n. 29, p. 96-112, 2015.

PRESTON, L. E. Research on corporate social reporting: directions for development. Accounts, Organizations and Society, v. 6, n. 3, p. 255-262, 1981.

REVERTE, C. Determinants of corporate social responsibility disclosure ratings by Spanish listed firms. Journal of Business Ethics, v. 88, n. 2, p. 351-366, 2009. 
RIZK, R.; DIXON, R.; WOODHEAD, A. Corporate social and environmental reporting: a survey of disclosure practices in Egypt. Social Responsability Journal, v. 4, n. 3, p. 306-323, 2008.

ROVER, S.; BORBA, J. A.; MURCIA, F. D. R. Características do disclosure ambiental de empresas brasileiras potencialmente poluidoras: análise das demonstrações financeiras e dos relatórios de sustentabilidade do período de 2005 a 2007. Contextus, v. 7, n. 1, p. 23-36, 2009.

SANTANA, L. M.; GÓIS, A. D.; DE LUCA, M. M. M.; VASCONCELOS, A. C. Relação entre disclosure socioambiental, práticas de governança corporativa e desempenho empresarial. Organizações em Contexto, v. 11, n. 21, p. 49-72, 2015.

SHOCKER, A. D.; SETHI, S. P. An approach to incorporating societal preferences in developing corporate social action. California Management Review, v. 15, n. 4, p. 97-105, 1973.

SILVA, L. S. A.; QUELHAS, O. L. G. Sustentabilidade empresarial e o impacto no custo de capital próprio das empresas de capital aberto. Gestão e Produção, v. 13, n. 3, p. 385-395, 2006.

SILVA, M. N.; LIMA, J. A. S. O.; FREITAS, M. A. L.; SILVA FILHO, L. L.; LAGIOIA, U. C. T. Determinantes do disclosure ambiental nos relatórios de empresas listadas na Bovespa. Revista Ambiente Contábil, v. 7, n. 2, p. 1-15, 2015.

SMITH, M.; YAHYA, K.; AMIRUDDIN, A. M. Environmental disclosure and performance reporting in Malaysia. Asian Review of Accounting, v. 15, n. 2, p. 185-199, 2007.

SOUSA, C. B.; SILVA, A. F.; RIBEIRO, M. S.; WEFFORT, E. F. J. Valor de mercado e disclosure voluntário: estudo empírico em companhias listadas na BM\&FBovespa. Revista Ambiente
Contábil, v. 6, n. 2, p. 94-115, 2014.

SOUZA, J. A.; SARLO NETO, A. Práticas de divulgação de informações sobre segmentos operacionais no Brasil. Sociedade, Contabilidade e Gestão, v. 9, n. 2, p. 40-57, 2014.

SJÖBERG, E. An empirical study of federal law versus local environmental enforcement. Journal of Environmental Economics and Management, v. 76, n. 1, p. 14-31, 2016.

SUCHMAN, M. Managing Legitimacy: Strategic and Institutional Approaches. Academy of Management Review, v. 20, n. 3, p. 571-601, 1995.

SUTTIPUN, M., \& STANTON, P. The differences in corporate environmental disclosures on websites and in annual reports: a case study of companies listed in Thailand. International Journal of Business and Manegement, v. 7, n. 4, p. 18-31, 2012.

TANNURIL, G.; VAN BELLEN, H. M. Indicadores de desempenho ambiental evidenciados nos relatórios de sustentabilidade: uma análise à luz de atributos de qualidade. Revista de Gestão Social e Ambiental, v. 8, n. 1, p. 2-19, 2014.

TEIXEIRA, L. M S.; RIBEIRO, M. S. Estudo bibliométrico sobre as características da Contabilidade Ambiental em periódicos nacionais e internacionais. Revista de Gestão Social e Ambiental, v. 8, n. 1, p. 20-36, 2014.

TELLES, S. V.; SALOTTI, B. M. Divulgação da informação contábil sobre depreciação: o antes e o depois da adoção das IFRS. Revista Universo Contábil, v. 11, n. 2, p. 153-173, 2015.

TEN, E. E. Determinants of environmental disclosure in a developing country: an application of the stakeholder theory. In: ASIA PACIFIC INTERDISCIPLINARY RESEARCH IN ACCOUNTING CONFERENCE, 4., Singapore, 2004. Anais... Singapore: APIRA, 2004. 
TEN, E. E. Applying stakeholder theory toanalyze corporate environmental performance: Evidence from Australian listed companies. Asian Review of Accounting, v. 15, n. 2, p. 164-184, 2007.

VIANA JUNIOR, D. B. C.; CRISÓSTOMO, V. L. Nível de Disclosure Ambiental das Empresas Pertencentes aos Setores Potencialmente Agressivos ao Meio Ambiente. Contabilidade, Gestão e Governança, v. 19, n. 2, p. 254-273, 2016.

VIEIRA, C. A. M.; ARRUDA, M. P.; LIMA, R. J. V. S. Custos ambientais de acordo com o potencial impacto poluidor listado pela lei $\mathrm{n}$ 10.165/2000: empresas potencialmente mais poluidoras têm mais gastos relacionados ao meio ambiente? In: CONGRESSO BRASILEIRO DE CUSTOS, 21., Natal, 2014. Anais... Natal: CBC, 2014.

VILLIERS, C.; ALEXANDER, D. The institutionalisation of corporate social responsibility reporting. The British Accounting Review, v. 46, n. 2, p. 198-212, 2014. 